\title{
Modelling of Driver's Gap Acceptance for Evaluation of Traffic Flow Characteristics at Unsignalized Intersection in Urban Area, Ethiopia
}

\author{
Fikedu Rage Faye \\ Department of Civil Engineering, Mettu University, Mettu, Ethiopia \\ Email address: \\ fikedu.rage@gmail.com \\ To cite this article: \\ Fikedu Rage Faye, Modelling of Driver's Gap Acceptance for Evaluation of Traffic Flow Characteristics at Unsignalized Intersection in \\ Urban Area, Ethiopia. American Journal of Traffic and Transportation Engineering. Vol. 5, No. 5, 2020, pp. 57-64. \\ doi: 10.11648/j.ajtte.20200505.12
}

Received: October 3, 2020; Accepted: October 19, 2020; Published: December 31, 2020

\begin{abstract}
Introduction: Studying microscopic traffic flow characteristics has vital role in reduction of traffic problems. Gap acceptance and waiting time are traffic characteristics that are used in capacity, delay and level of service at unsignalized intersection. A lot of studies related to gap acceptance and waiting time has been done in developed countries under homogeneous traffic and road conditions. Objectives: This study is aimed to insight gap acceptance and waiting time behavior of merging or crossing vehicles in urban intersection under heterogeneous traffic condition and weak lane discipline in developing country like Ethiopia. Methods: In this paper three unsignalized intersection in Adama city has been selected on the basis of traffic volume and importance of the intersection. The primary data that were used for this study were traffic volume, speed, headway, waiting time, geometry of road, gap accepted and rejected. By using digital Camera, videos data were recorded; later quantitative data were extracted from videos. Two Statistical Packages that were used in analysis of this study. Minitab 19 was used for developing regression models of waiting time and gap acceptance for two maneuver types namely traffic turning to left and turning right from minor road. Result: Dichotomous generalized linear regression model (logit model) has been used to predict gap acceptance probability and validated by Hosmer-Lemeshow testing techniques to identify the goodness of model. The waiting time of drivers to accept and reject available gaps for three selected intersections were about $26 \mathrm{sec}, 24 \mathrm{sec}$ and $20 \mathrm{sec}$. From the developed nonlinear model traffic turning to left moving with average speed $30 \mathrm{kmph}$, average headway of $10 \mathrm{sec}$ and minor road traffic volume $2000 \mathrm{PCu} / \mathrm{Hr}$, increasing $25 \%$ major road traffic volume makes to double waiting time on minor road. Increasing major road traffic volume by $50 \%$ makes to quadruple waiting time.
\end{abstract}

Keywords: Gap Acceptance, Headway Distribution, Logit Model, Maneuver Type, Waiting Time

\section{Introduction}

In modern life transportation is one of basic needs that has complex in its nature. Complexity is due to dynamic property of transportation facilities and rapid growth of traffic. Gap acceptance is one of the most important elements in microscopic traffic characteristic which is an indispensable in the determination of capacity and delay of the individual moment at uncontrolled intersection. A significant effort has been made in order to study the traffic volume study in India by Singh B and Tripta G [15].

A lot of study was done in developed country concerning, gap size distribution and gap acceptance for uncontrolled intersection where homogeneous and lane discipline is mandatory. Gap acceptance is an important characteristic for analyzing specially at uncontrolled intersections. Gap acceptance models are strongly affected by driver behavior and local habits. Follow-up headways can be field measured, while critical headway cannot be obtained directly as shown by Gazzari [8]. The behavior of different vehicle types and gap of subject vehicle type from minor street taking right turn to merge with major traffic stream is analyzed using gap acceptance method was also used by Doddapaneni et al. [5]. Two intersection of different legs were selected, with three maneuver types of overtaking. Sangole, J. P. and Patil, G. R. [13] provided that gap acceptance theory is broadly used for evaluating unsignalized intersections in developed countries.

Farah et al. [7] modeled binary logistic model for passing 
gap acceptance by considering road geometry, traffic conditions and drivers' characteristics. It was found that while the traffic related variables had the most important effect on passing decision, factors related to the geometric design and the driver characteristics also had a significant effect on these decisions. Abhishek and Marko [2] developed model for Traffic flow that merges into a main flow. The merging times required for two subsequent vehicles will be strongly correlated as they experience similar traffic conditions on the main flow.

Study conducted by Rashmi and Srikanth. R [11] forwarded engineering remedial measures after analyzing all the data of traffic flow characteristics such as: widening of road, increasing the number of lanes, providing medians or separators between the opposite lanes, improving the footpath condition and providing skywalks or pedestrian cross over where the congestion is more.

\subsection{Need for Present Study}

In urban area at unsignalized intersection where traffic congestion is serious problem studying traffic flow characteristics is essential activity to take action and tackle the problem. Adama is one of Ethiopian city which have high traffic flow since its location is found to be exit-entrance corridor. Due to Adama city is center of business peoples come to this city for conference, for merchandizing goods and for recreational purpose heavy traffic movement is observable. Traffic movement is mixed traffic and the flow characteristic varies from place to place and with period of time. Since the vehicle and pedestrian behavior is not fixed in nature. Adama city traffic office report shows $21 \%$ of accident occurred due to lack of understanding minimum accepted (un necessary overtaking). Congestion and delay also occurred because of by rejecting large gaps by drivers. The researcher is initiated to put his own role by doing scientific research on gap acceptance and waiting time to accept available gaps gives some understanding for road users (drivers, passengers and pedestrians) and professionals.

\subsection{Objective of Study}

In general, the aim of this study gap acceptance and waiting time behavior of drivers to evaluate traffic flow characteristics for merging or crossing drivers to major road from minor road at unsignalized intersection for variable road and traffic condition.

\subsection{Review Literature}

At times traffic analysts face difficulties in characterizing and modeling such congested flow of traffic, thereby, addressing this issue effectively. Since a key component of determining the performance of a simulation model is the generation of inter-arrival times or headways as an input into the simulation process, it is imperative to have reliable and practical descriptions of gaps has been done by Rupali, R. [12].

Bartin [4] developed logit model of gap acceptance and rejectance depending up on the following influencing factors; maneuver type, time of day, time spent waiting for an acceptable gap, average speed, departure zone (i.e., median or minor road departure point), and vehicle classification here are a lot of many methods, which calculate the critical headway, Dutta [6] used that; using binary logistic model they analyzed and develop gap acceptance behavior on minor street at uncontrolled intersections in northwestern India. Critical Gap acceptance were calculated by using maximum likelihood approach by considering influencing factors of gap duration, clearing time, aggressiveness of drivers. Field data were for three uncontrolled intersection used as input. Speed and volume data also recorded by video graphic technique. Later data were extracted at home form digital camera. Finally, Gap acceptance models are also developed considering gap duration and clearing time. Forced entry into the intersection is not considered in these models, which mean that all the minor street drivers clearing the intersections are deemed to behave alike.

\section{Materials and Methods}

\subsection{Location of Study}

The study area is Adama city which is located in Ethiopia, Oromia national regional state, east Showa zone at a distance of $99 \mathrm{~km}$ from the capital city of Ethiopia, Addis Ababa. Adama city is located at $8.54^{\circ} \mathrm{N}$ and $39.27^{\circ} \mathrm{E}$.

\subsection{Road Condition}

The road which connect Aba Geda to Kella is major road which goes to Diredawa-Djibouti. In this city there are many intersections namely; roundabout, T-Intersection, YIntersection and 4-legged intersection. After Pilot survey conducted on all intersection of Adama city and traffic conditions were identified, intersection was selected. The selection of Intersection was generally based on: Where traffic volume is most likely high, high percentage of heavy traffic, unsignalized or uncontrolled intersection, presence of mixed traffic and variable road geometric conditions, the number of pedestrians which can be obstacle during merging or crossing Three unsignalized intersection that were selected for this study were; Franko Intersection, Tikur Abay intersection and Wonji mazoria intersection.

Table 1. Selected Intersection for the study.

\begin{tabular}{|c|c|c|c|c|c|}
\hline $\mathbf{S} / \mathbf{N}$ & Name of Intersection & Major Approach & Minor Approach & Major Road Width & Minor Road Width \\
\hline 1 & Franko & Postabet-W/Mazoria & Selassie-Franko & 12.4 & 11.6 \\
\hline 2 & Tikur Abay & Postabet -Adisu Menehara & Tikur Abay-Kella & 9.6 & 9.4 \\
\hline 3 & Wonji Mazoria & W/Mazoria- Duket & Postabet-Aba Geda & 12.00 & 9.6 \\
\hline
\end{tabular}




\subsection{Data Collection and Survey Method}

Various primary data were collected at three unsignalized intersection in Adama City. All the three Intersection approaches were divided with median means that major and minor roads are two lane one way roads separated by median. The Primary data that were used for the study were; Traffic on major Street, Traffic on minor street, Pedestrian, Speed on major Street, Waiting time (delay), Headway or gap Size, Gap acceptance and rejectance, Road geometry

\subsubsection{Traffic Volume Counting}

This volume study was conducted for three selected unsignalized intersection of Adama City both at peak and non-peak hour for 12 hours at fifteen-minute time interval
(7:00 AM morning-7:00 PM night). The volume counting was for three days namely; Monday, Thursday and Saturday. These days were selected up on conducted pilot survey. Means those days which traffic movement is so high. Accordingly, from weekday two days were selected and one day from weekend. The volume and composition of the traffic passing along the road between was conducted by using manual method. A reference is fixed by observing land use and traffic condition. This reference place is located far from junction because it is the point there is normal traffic flow on corridor. The enumerator is standing near the reference line and records the vehicles while crossing the reference lines regarding to categories.

Table 2. Major road total traffic Volume Counted in PCU for Selected Intersection.

\begin{tabular}{lllll}
\hline \multirow{2}{*}{ Intersection Name } & \multirow{2}{*}{ Origin-Destination } & \multicolumn{2}{l}{ Date of data collected } & \\
\cline { 3 - 5 } & & $\mathbf{1 5 / 0 4 / 2 0 1 9}$ & $\mathbf{1 8 / 0 4 / 2 0 1 9}$ & $\mathbf{2 0 / 0 4 / 2 0 1 9}$ \\
\hline Franko & Posta Bet-Franko-Wonji Mazoria & 12951 & 11140 & 14160 \\
Tikur Abay & Posta Bet -Tikur Abay-Addisu-Menehara & 10434 & 9706 & 13722 \\
Wonji Mazoria & Franko-Wonji Mazoria-Awura Godana & 10775 & 16851 & 12369 \\
\hline
\end{tabular}

\subsubsection{Gap Acceptance and Waiting Time Data Collection}

In collection of gap acceptance data video graphic technique was used, means video was recorded later data were extracted from videos. When extracted videos stop watch was used. In collection of gap acceptance data headway (gap) accepted was coded as 1 and rejected was coded as 0 .

\subsubsection{Speed Data Collection}

The speed of the vehicle measured on a given road, when the vehicle is moving by considering all the delays that occurs during their journey time. For all practical purposes, spot speeds of the vehicles are conducted for the analysis of any traffic problem in urban areas. running Speed and journey speeds are considered.

1. Selection of the Proper Location and Layout

2. Making reference lines

3. Record Observations on Stopwatch in sheet prepared

4. Conversion of Travel Time to Travel Speed

Speed is ratio of Distance traveled to elapsed time. by taking average travel time of $50 \mathrm{~m}$ distance travel speed was calculated.

\subsubsection{Headway}

In order improve accuracy, the data were collected by vedographic method by using digital camera. video was recorded for $12 \mathrm{hrs}$. Starts from 7:00 am to 7:00 pm. Later data were extracted by using stop watch. The vehicle arrivals were noted down by the observers. The difference of time arrivals between the two successive vehicles then gave the time headway between the two vehicles.

\subsubsection{Pedestrian Volume}

Pedestrian blockage refers to the situation in which a pedestrian is crossing at the intersection. A pedestrian can cause major-street vehicles to stop if the pedestrian is crossing the major street, or eliminate the opportunity for a minor-street vehicle to seek gaps while the path is being blocked by the pedestrian has been shown by Tian. Z. [16]. When a pedestrian blocks the major street, the minor-street vehicles may move through the intersection at the same time, causing drivers to accept large gaps. When pedestrian crosses the minor street, the minor-street driver has no chance to judge major-street gaps, which may cause him or her to reject large gaps. If the proposed method is used, data obtained during pedestrian blockages should be eliminated. The number of pedestrian that blocks minor stream to cross or merge to major Street was counted and later converted to traffic by passenger car unit.

\subsubsection{Road Geometry Measuring}

The road geometry of Major and Minor road has great influence on traffic flow characteristics like headway, speed, volume, delay on Intersection and gap accepting conditions.

Table 3. Geometric Characteristic of Major and Minor Road in meters.

\begin{tabular}{llllll}
\hline \multirow{2}{*}{ Intersection Name } & Major Road & & Minor Road & Date of Surveyed \\
\cline { 2 - 5 } & Road Width & Shoulder Width & Road Width & Shoulder Width & $12 / 05 / 2019$ \\
\hline Franko & 12.4 & 1.2 & 11.6 & 1.2 & $16 / 05 / 2019$ \\
Tikur Abay & 9.6 & 0.80 & 9.4 & 0.80 & $17 / 05 / 2019$ \\
Wonji Mazoria & 12.0 & 1.00 & 9.6 & 1.00 & \\
\hline
\end{tabular}


Materials and tools Used: Various materials/tools and software's that were used in accomplishing of this study were; digital camera, tripod, stopwatch, mobile phone, paint and chalk, data record sheet. In collection primary data digital camera with tripod were used for video graphic recording. Stop watch has been used to collect headway, travel time for speed data, gap accepted and rejected. Paint and chalk was used to mark reference line for data collection. AutoCAD 2007 for sketching of geometry of intersection under study area. GIS and Google Earth were used to subset and show real image of study area.

\section{Result and Discussion}

This section includes investigation and detail of study, quantitative data analysis, development of models testing fitness (validation) was done for evaluation of traffic flow characteristics for selected unsignalized intersection in Adama city.

\subsection{Traffic Volume Data Analysis}

Traffic volume and composition is the most important characteristics which used in calculating the equivalent flow rate, thereby determination level of service on the road network. It is also useful in dividing traffic trips on different modes of vehicles that known in transportation engineering as a "Mode Split" or Modal split or Mode [1].

Passenger car equivalent (PCE) is an important factor which is used to convert traffic volumes containing proportions of heavy good vehicles (HGVs) to a unify measure containing only passenger cars units (PCU) [3].

Total traffic volume in PCU used for this study with respective traffic categories has been shown on Figure 1. On major road of Tikur Abay Intersection Bajaj is vehicle category that was observed abundantly and more than 6000PCU. On the major road of Wonji Mazoria intersection small bus covers high proportion. Among traffic categories car was highly observed on major road of Franko Intersection.

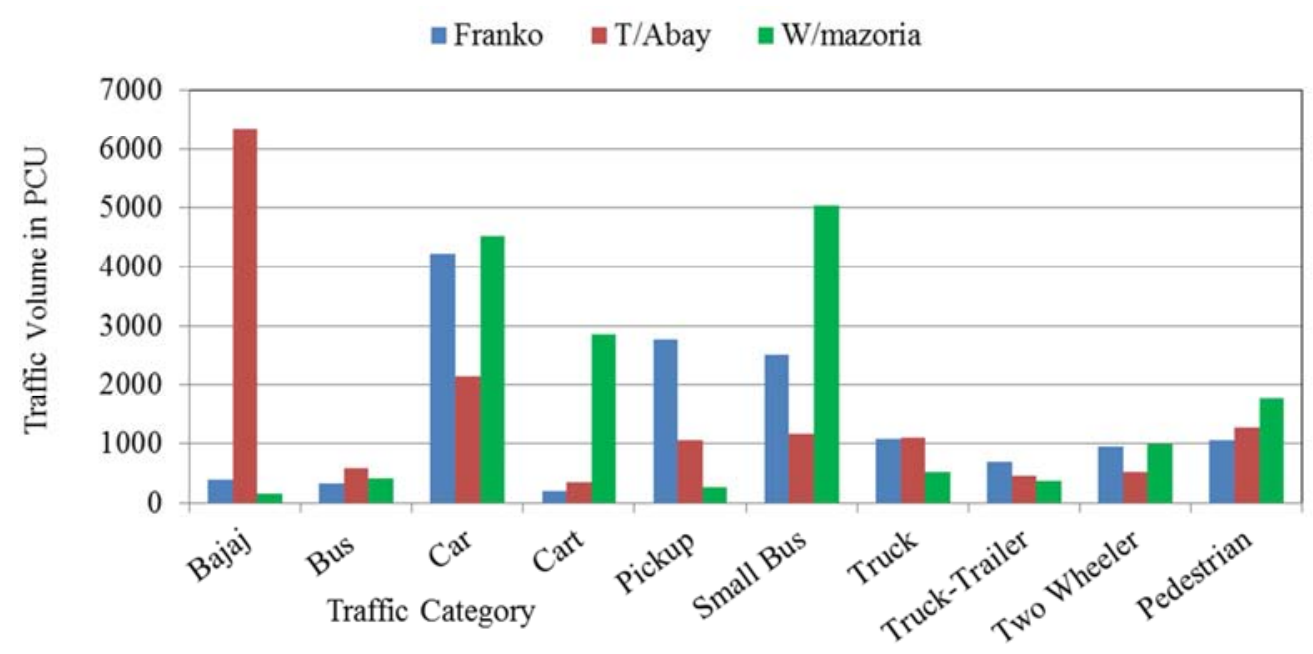

Figure 1. Total Traffic Volume Major Stream in PCU.

Their values are not more than one. Small peak hour means greater variability of traffic flow in an hour where as high peak hour means less variability of flow in an hour. When the PHF is known, it can convert a peak hour volume to a peak flow Rate, as in Equation

$$
v=\frac{V}{P H F}
$$

Where $\mathrm{v}$ is the flow rate for a peak 15-minutes, expressed in vehicles per hour, and the other variables are as defined previously.

\subsection{Speed Percentiles on Major Roads}

Speed is a significant transportation constraint as it is directly linked to safety, time, comfort, convenience, and financial side for any type of road and required for better management of the stream [14].

In the case of heterogeneous traffic condition percentile of speed has vital role in explaining traffic characteristics of the area. Geometric design or renewal existing facilities and traffic regulation are depending on the cumulative number of traffic that are maintain certain speed.

To compute the percentiles of speed at 15\%, 50\% and $85 \%$, ordering speed from lowest to largest. For computation rank Montgomery [9] provides the following statistical equation.

Rank $=\frac{\text { Percentile }}{100} *(n+1)$, where $\mathrm{n}$ is sample size. One typical example of method used to determine $15 \%$ percentile of speed of vehicles with sample size (n) 144. Rank $=15 / 100(144+1)=0.015^{*} 145=21.75=22$ by rounding up. So that the $15^{\text {th }}$ percentile of operating speed is found on $22^{\text {nd }}$ from lowest to largest which is $23 \mathrm{kmph}$ for Bajaj. For all traffic categories the same procedures have been followed.

In this Study three commonly used speed percentiles were calculated for each category of traffic. The $15^{\text {th }}, 50$ th and 85 th percentiles of speed have been shown on the Figure 2. 
For Franko intersection major road $85 \%$ of the vehicles are moving less than $30 \mathrm{kmp}$ for all categories of vehicles. And also $50 \%$ and $15 \%$ of vehicles moving on major road of Franko intersection were maintaining operating speed less than $25 \mathrm{kmph}$ and $20 \mathrm{kmph}$ respectively. For a major stream of Tikur Abay intersection $85 \%$ of the vehicles were maintaining less than $30 \mathrm{kmp}$. A $50 \%$ of traffic moving on major road of Tikur Abay are maintaining less than $35 \mathrm{kmph}$ in case of Bajaj, Bus, Pickup, Small Bus. And also Two Wheeler maintaining speed less than $25 \mathrm{kmph}$. And also $15 \%$ of vehicles moving on major road of Tikur Abay Intersection are maintaining speed less than $25 \mathrm{kmph}$ in case of Bajaj, Cart, Pickup, Small Bus, Truck and Truck-Trailer. A $85 \%$ of major stream of Wonji Mazoria are maintaining speed less than $30 \mathrm{kmph}$ for Bajaj, Truck and Truck-Trailer.

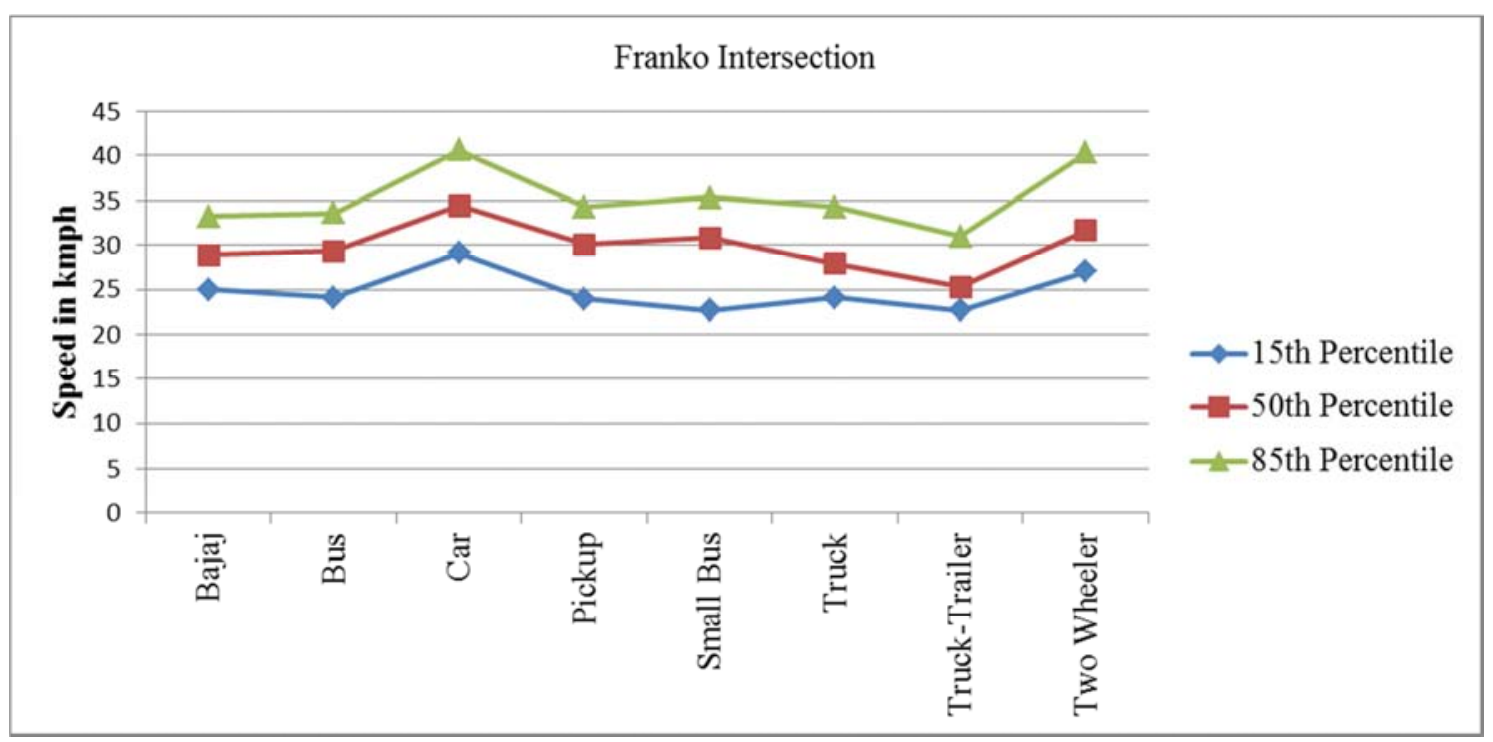

Figure 2. Percentiles of Speed on Major Road of Study Area.

\subsubsection{Gap Acceptance Model for Traffic Turning to Left}

Most of the capacity calculation procedures for two-way stop-controlled (TWSC) intersections are based on gap acceptance models [16]. Logistic Regression analysis was performed on the secondary characteristics drivers whether involvement of crash by [10].

Here in this study binary logistic regression (logit model) of gap acceptance for traffic turning to left developed and has been shown in the below equation.

$$
\mathrm{P}(1)=\exp \left(\mathrm{Y}^{\prime}\right) /\left(1+\exp \left(\mathrm{Y}^{\prime}\right)\right)
$$

$\mathrm{Y}^{\prime}=-19.8+0.00263 \mathrm{Qma}-0.00649$ Qmi-0.093V + 3.35GS + 0.183 WT, which can be generalized as

$$
\mathrm{P}(1)=\frac{e^{-19.8+0.00263 Q m a-0.00649 Q m i-0.093 V+3.35 G S+0.183 W T}}{1+e^{-19.8+0.00263 Q m a-0.00649 Q m i-0.093 V+3.35 G S+0.183 W T}}
$$

where, P (1): probability of gap acceptance, Qma; Opposing traffic volume in PCU, Qmi: Minor road traffic volume in PCU, GS: Available Gap Size and WT: Waiting Time.

Table 4. Coefficients and Odds Ratios for Continuous Predictors.

\begin{tabular}{llllll}
\hline Term & Coef & SE Coef & VIF & Odds Ratio & 95\% CI \\
\hline Constant & -19.8 & 11.6 & & 1.0026 & $(0.9939,1.0114)$ \\
Qma & 0.00263 & 0.00445 & 4.60 & 0.9935 & $(0.9826,1.0046)$ \\
Qmi & -0.00649 & 0.00566 & 5.64 & 0.9115 & $(0.5907,1.4064)$ \\
V & -0.093 & 0.221 & 1.09 & 28.4049 & $(2.8964,278.5653)$ \\
GS & 3.35 & 1.16 & 2.38 & 1.2006 & $(0.6977,2.0662)$ \\
WT & 0.183 & 0.277 & 1.77 & 1.0026 & $(0.9939,1.0114)$ \\
\hline
\end{tabular}

Interpretation: Regardless of a number of covariates (Gap Size, Major road traffic, Minor road traffic, and waiting time) values, if they are assumed to be zero, then the probability of accepting available gaps will be; $\mathrm{P}$ (Gap Accept) $=\frac{e^{-19.8}}{1+e^{-19.8}}=4.10 * 10^{-5}$ which is small number. It is approximated to be zero means available gap will be rejected., If the constant is zero $\beta_{0}=0$, then probability of accepting gap will be; $\mathrm{P}$ (Gap Accept) $=\frac{e^{0}}{1+e^{0}}=0.5$ it known 
as base line (Event rate). Negative values of $\beta_{0}$ gives probability of gap acceptance rate (baseline) less than 0.5 and positive values of $\beta_{0}$ constant give probability of acceptance greater than 0.5 . The change in one unit of predictor (opposing traffic flow, minor road volume, speed, available gap size and waiting time on minor road) associated with logit of the response variable (gap acceptance) in coefficients of, $0.00263,0.00649,0.093,3.35$, and 0.183 respectively. Means that one unit change in opposing traffic volume leads to change logit of response variable by 0.00263 . From estimated coefficients from model it is observed that gap size, waiting time and speed have strong effect in changing outcome variables (gap acceptance).

In above gap acceptance model VIF (Variance inflation Factor) is almost less than 5 except for minor road volume, which means model is good in expressing the relationship between gap acceptance and factors influencing it. A lot of researchers uses VIF less than 10. For better model it should be less than 5 which has been provided by Montgomery, D. C [9]. Odds ratio in respect of waiting time approximately to 1 means that exposure to property of accepting gap does not affect the odds of rejecting gaps. Since odds ratio more than 1 in respect of speed and available gap size means that there is a higher odds of property rejecting gaps happening with probability to accepting gap. An odds ratio is less than 1 is associated with lower odds gap acceptance in respect of number opposing vehicles, minor road volume and major road.

In general odds ratios that are greater than 1 indicate that the probability of accepting available gaps is more likely to occur as the predictors (speed and available gap size) increases. Odds ratios that are less than 1 indicate that the probability of accepting available gap is less likely to occur as the predictor (traffic volume on major and minor road) increases.

Table 5. Model Summary and Goodness-of-Fit Tests.

\begin{tabular}{lllll}
\hline Deviance R-Sq & Deviance R-Sq (adj) & AIC & AICc & BIC \\
\hline $87.43 \%$ & $84.81 \%$ & 35.95 & 36.56 & 53.77 \\
Goodness-of-Fit Tests & & & & \\
Test & DF & Chi-Square & P-Value & \\
Pearson & 138 & 369.35 & 0.000 & \\
Hosmer-Lemeshow & 8 & 4.76 & 0.783 & \\
\hline
\end{tabular}

\subsubsection{Testing and Validation of Model}

In this study Pearson, likelihood ratio test and HosmerLemeshow tests were used. Adjusted deviance R-Sq, AIC and BIC, values were estimated from model and evaluated significance level less than 0.05 . These values used to test the goodness of fit the model has been shown in Table 5. It is observed adjusted deviance $\mathrm{R}-\mathrm{Sq}$ has been used to compare models that have different numbers of predictors. Deviance $\mathrm{R}-\mathrm{Sq}$ always increases when you add a predictor variable to the model.
In analysis of variance likelihood ratio statistic provides that how much the model predicts decision whether accepting gap or rejecting gaps. Since chi-square of likelihood ratio 166.58 with $p$-value of less than significant level (0.05), which is large number the model good in predicting gap acceptance with the given covariates. Table 6 shows how the researcher used Hosmer-Lemeshow to show the goodness-offit of gap acceptance model to compares the observed and expected frequencies of gap accepted and gap rejected to assess how well the model fits the data.

Table 6. Observed and Expected Frequencies for Hosmer-Lemeshow Test.

\begin{tabular}{|c|c|c|c|c|c|}
\hline \multirow{2}{*}{ Group } & \multirow{2}{*}{$\begin{array}{l}\text { gap acceptance } \\
\text { probability ranges }\end{array}$} & \multicolumn{2}{|c|}{ GA = 1 (Gap Accepted) } & \multicolumn{2}{|c|}{ GA = 0 (Gap Rejected $)$} \\
\hline & & Observed & Expected & Observed & Expected \\
\hline 1 & $(0.000,0.004)$ & 0 & 0.0 & 14 & 14.0 \\
\hline 2 & $(0.004,0.022)$ & 1 & 0.2 & 13 & 13.8 \\
\hline 3 & $(0.022,0.051)$ & 0 & 0.5 & 15 & 14.5 \\
\hline 4 & $(0.051,0.235)$ & 0 & 1.9 & 14 & 12.1 \\
\hline 5 & $(0.235,0.613)$ & 4 & 5.5 & 11 & 9.5 \\
\hline 6 & $(0.613,0.853)$ & 14 & 11.1 & 0 & 2.9 \\
\hline 7 & $(0.853,0.921)$ & 14 & 12.5 & 0 & 1.5 \\
\hline 8 & $(0.921,0.941)$ & 15 & 14.0 & 0 & 1.0 \\
\hline 9 & $(0.941,0.984)$ & 13 & 13.5 & 1 & 0.5 \\
\hline 10 & $(0.984,1.000)$ & 13 & 14.9 & 2 & 0.1 \\
\hline
\end{tabular}

The researcher used Hosmer-Lemeshow to test the goodness-of-fit test by comparing the observed and expected frequencies of gap accepted and rejected to evaluated how well the model fits the data. The goodness-of-fit tests to determine whether the predicted probabilities deviate from the observed probabilities. for the deviation. 

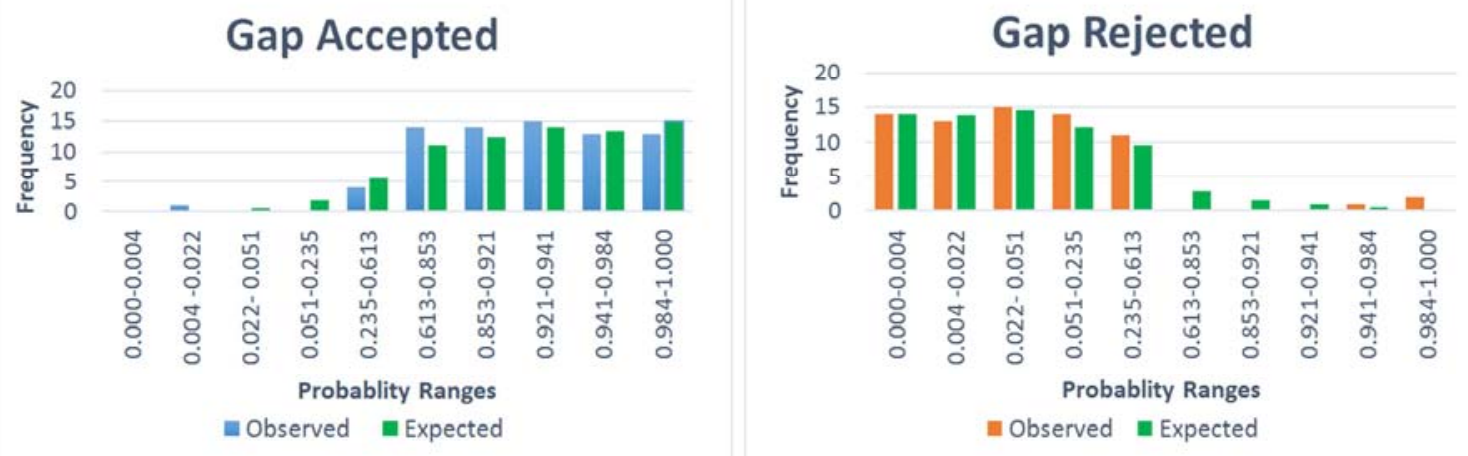

Figure 3. Observed and Expected Frequencies for Left Turning.

\subsubsection{Modelling of Gap Acceptance for Traffic Turning to Right}

For traffic turning to right also the researcher has been developed model by considering the same parameters (i.e.: opposing traffic volume, minor road volume, speed on major road, available gap size and waiting time on minor road). developed model for probability of accepting available gap has been shown below.

$$
\mathrm{P}(1)=\exp \left(\mathrm{Y}^{\prime}\right) /\left(1+\exp \left(\mathrm{Y}^{\prime}\right)\right)
$$

$\mathrm{Y}^{\prime}=-40.9-0.00608$ Qma -0.00437 Qmi-0.213 V + 3.28 GS + $0.332 \mathrm{WT}$,

which can be generalized as:

$$
\mathrm{P}(1)=\frac{e^{-40.9-0.00608 \mathrm{Qma}-0.00437 \mathrm{Qmi}-0.213 \mathrm{~V}+3.28 \mathrm{GS}+0.332 \mathrm{WT}}}{1+e^{-40.9-0.00608 \mathrm{Qma}-0.00437 \mathrm{Qmi}-0.213 \mathrm{~V}+3.28 \mathrm{GS}+0.332 \mathrm{WT}},}
$$

where,

P (1): probability of gap acceptance, Qma; Opposing traffic volume in PCU, Qmi: Minor road traffic volume in PCU, GS: Available Gap Size and WT: Waiting Time.

From Table 7 positive values of coefficients means the probability of gap acceptance is more likely at the level of predictors (opposing traffic flow, minor road volume, speed, available gap size and waiting time on minor road) than reference level or $\mathrm{P}(\mathrm{Gap}$ Accept $)=\frac{e^{-40.9}}{1+e^{-40.9}}=0$. And also negative coefficient means the probability of gap acceptance less likely at the level of predictors than at reference level. Positive coefficients for gap size and waiting time means increasing values of these values make drivers more likely to accept the gaps and negative coefficients for opposing minor road, major road traffic volume and speed makes the to accept less likely or reject gaps.

\begin{tabular}{|c|c|c|c|c|c|}
\hline Term & Coef & SE Coef & VIF & Odds Ratio & $95 \% \mathrm{CI}$ \\
\hline Constant & -40.9 & 19.7 & & - & - \\
\hline Qma & -0.00608 & 0.00435 & 2.49 & 1.0061 & $(0.9975,1.0147)$ \\
\hline Qmi & -0.00437 & 0.00400 & 2.32 & 1.0044 & $(0.9965,1.0123)$ \\
\hline V & -0.213 & 0.296 & 1.19 & 1.2373 & $(0.6924,2.2110)$ \\
\hline GS & 3.28 & 1.13 & 5.98 & 26.5074 & $(2.9178,2.8095)$ \\
\hline WT & 0.332 & 0.462 & 3.60 & 1.3943 & $(0.5639,3.4475)$ \\
\hline
\end{tabular}

Table 7. Coefficients and Odds Ratios for Continuous Predictors.

Interpretation: Positive values of regression coefficients make gap acceptance more likely and negative values of regression coefficients indicate gap acceptance less likely to occur. Consider regression coefficient of model respect to waiting time, 0.332 which is positive increase waiting time to induce more likely the probability of gap acceptance than base line or event rate. And also for negative coefficients increase consider traffic volume, increasing number volume makes gap acceptance less likely which means rejecting gaps.

Table 8. Model Summary and Goodness-of-Fit Tests.

\begin{tabular}{llll}
\hline Deviance R-Sq & Deviance R-Sq (adj) & AIC & AICc \\
\hline $83.37 \%$ & $80.85 \%$ & 44.96 & 45.58 \\
Goodness-of-Fit Tests & & & BIC \\
Test & DF & Chi-Square & P-Value \\
Deviance & 138 & 32.96 & 0.000 \\
Pearson & 138 & 116.29 & 0.910 \\
Hosmer-Lemeshow & 8 & 4.42 & 0.817 \\
\hline
\end{tabular}

From Table 8 deviance R-squared $83.37 \%$ and Chi-square is positive large number with $\mathrm{P}$-value 0.000 HosmerLemeshow Test was used in order to test the model fitness at

\section{$95 \% \mathrm{CI}$}

The model has been validated in such a way that the gap acceptance probability has been divided into ten groups and 
evaluated for rejected and accepted gap separately. Observed

probability expected are compared for each ten groups.

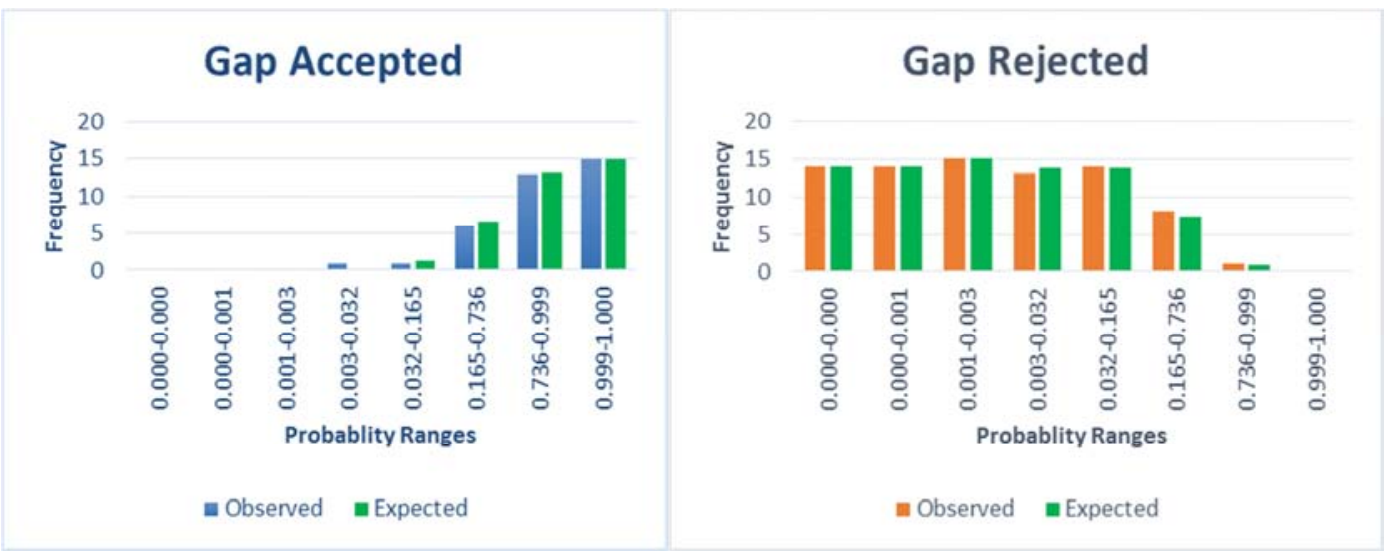

Figure 4. Observed and Expected Frequencies for Right turning.

\section{Conclusion}

This paper presents a detail study of driver's gap acceptance of unsignalized intersection under mixed traffic condition and weak lane disciplined urban unsignalized intersection. It has been investigated the percentages of heavy traffic $32 \%, 22 \%$, and $37 \%$ for Franko, Tikur Abay and Wonji Mazoria intersection. The observed operational speed $28 \mathrm{kmph}$ to $35 \mathrm{kmph}$ depending up on vehicle category. The 15, 50 and 85 percentiles of speed were 24,29 and $35 \mathrm{kmph}$ respectively.

For low flow rates less than 500PCU/Hr, average speed of $20 \mathrm{kmph}$ and large headway more than $25 \mathrm{sec}$ waiting time not more affected by traffic volume on major road. For the turning to right the minor road volume has high influence on waiting time. Developed logit model to predict the probability of drivers to accept and to reject available headway for both maneuver type shows that increasing waiting time on minor road forces drivers to accept even little gap for which leads to get accident.

Generally Safe crossing of vehicles and merging of vehicles from minor road to major road, for the lane width less than $3.6 \mathrm{~m}$ and the traffic volume on the major road should not be more than 2200PCU/Hr and the critical headway on the major road should not be less than $4.56 \mathrm{sec}$ and $4.48 \mathrm{sec}$ respectively.

\section{References}

[1] Abdelaziz et al. (2018). The Effect of Traffic Composition on PCU Values and Traffic characteristics. IOSR Journal Of Humanities And Social Science (IOSR-JHSS), 3-1.

[2] Abhishek, Boon MAA, Boxma OJ, Núñez Queija R (2017) A single server queue with batch arrivals and semi-Markov services. Queueing Syst 86 (3-4): 217-240.

[3] Al-Obaedi, Jalal. (2016) Estimation of Passenger Car Equivalents for Basic Freeway Sections at Different Traffic Conditions. World Journal of Engineering and Technology. Vol 4. P155.

[4] Bartin et al., O. (2017). Simulation of Vehicle ' Gap Acceptance Decision Using Reinforcement Learning. Uludağ
University Journal of The Faculty of Engineering, 161-178.

[5] Doddapaneni et al., A. (2017). Multi Vehicle-Type Right Turning Gap Acceptance and Capacity Analysis at Uncontrolled Urban Intersections. Periodica Polytechnica Transportation Engineering, 1-9.

[6] Dutta, M. M. (2018). Gap acceptance behavior of drivers at uncontrolled T-intersections under mixed traffic conditions. Journal of Modern Transportation, 119-132.

[7] Farah et al., H. (2009). A passing Gap Acceptance model for two lane rural highway. Transportmetrica, 159-172.

[8] Gazzari et al., A. (2013). "Gap Acceptance Parameters for HCM 2010. Intersections Control and Safety, 13-14.

[9] Montgomery, D. C. (2003). Applied Statistics and Probability for Engineers. Arizona: Library of Congress Cataloging.

[10] O. A. Osman, S. Ishak, and M. Ye,(2017) "Crash Risk Aanlysis of Distracted Driving Behavior: Inluence of Secondary Task Engagement and Driver Characteristics," in Proceedings of the 5th Annual International Conference on Architecture and Civil Engineering pp. 42-45.

[11] Rashmi SM, \& Srikanth R. (2017). Study of traffic flow characteristics and remedial measures to overcome congestion. International research journal Engineering and technology, 1857-1860.

[12] Rupali, R. (2018). Headway Distrubution model of two lane roads under mixed Traffic conditions. European Transport Research Review, 1-12.

[13] Sangole, J. P., Patil, G. R. (2014). Adaptive neuro-fuzzy interface system for gap acceptance behavior of right-turning vehicles at partially controlled T-intersections. Journal of Modern Transportation. 22 (4), pp. 235-243.

[14] Shah, P. M., \& Gupta, N. (2017). Analysis of Speed Parameters of Mixed Traffic Flow on the Sections of Arterial Streets. Indian Journal of Science and Technolog, 1-7.

[15] Singh B, Tripta G. Study of traffic volume and level of service of Panjab University, Chandigarh International Journal of Engineering Research and Applications. 2015 Jul; 5 (7): 9-14.

[16] Tian, Z. (1999). Implementing the maximum likelihood methodology to measure a driver's critical gap. Transportation Research Part A 33, 187-197. 